\title{
Compromised Agency: The Case of BabyLegs
}

\author{
MAX LiBOIRON ${ }^{1}$ \\ MEMORIAL UNIVERSITY OF NEWFOUNDLAND
}

\begin{abstract}
The concept of agency is ubiquitous in STS, particularly regarding cases of alternative ways of knowing and doing science such as civic, citizen, and feminist sciences, among others. Yet the focus on agency often glosses over the constraints placed on agents, particularly within asymmetrical power relations. This article follows the case of BabyLegs, a do-it-yourself monitoring tool for marine microplastic pollution, and the attempt to keep the technology open source within an intellectual property (IP) system set up to privatize it. The tactics used to design BabyLegs as a feminine, silly, doll-tool to discredit the device in the eyes of an IP system that valued traditional gender roles lead to the eventual success of keeping the device open source. Yet, those same tactics also reinforced and reproduced the structures of power and essentialism they were designed to resist. I characterize this technological ambivalence as compromise, and argue that all agency exercised within asymmetrical power relations is compromised. This is not to say resistance is futile, but that agency is never pure, and this recognition lets us be more intentional in how we might compromise as practitioners of diverse scientific knowledges.
\end{abstract}

\section{Keywords}

intellectual property; open science; making and doing; feminist technology; environmental monitoring

\section{Compromised Agency: The Case of BabyLegs...We'll Need Some Tools}

Science requires tools. Who makes these tools, who uses them, how they are used, and how they work are deeply political questions embroiled implicitly or explicitly in struggles over what can

\footnotetext{
${ }^{1}$ Max Liboiron, Email: mliboiron@mun.ca

Copyright (C) 2017 (Max Liboiron). Licensed under the Creative Commons Attribution Non-commercial No Derivatives (by-nc-nd). Available at estsjournal.org.
} 
be known, what can make sense, and who can make sense (Winner 1980; Barad 2007; Harding 2016). Scientific tools within the petrochemical complex are particularly stark illustrations. For instance, though research and development on fracking in the United States has received \$137 million from the US Department of Energy, "no affordable technologies have been developed for communities to use to monitor their own air or water, even though access to the relevant data from industry is difficult" to obtain (Liboiron \& Molloy 2017; also see other articles in this thematic collection).

Scientists in low-GDP countries, grassroots community organizations, and citizen scientists "can struggle to obtain and maintain tools they require to answer their own research questions" (Liboiron \& Molloy 2017). STS theorist Langdon Winner's work on technological development applies equally to scientific tools, where "the very process of technical development is so thoroughly biased in a particular direction that it regularly produces results counted as wonderful breakthroughs by some social interests and crushing setbacks by others" (1980, 125). To bend technological development towards new social interests, the Open Science Hardware Movement (OSciH) "seeks to [challenge] these norms with the goal of providing different futures for science, using hardware as a launching point. It argues that plans, protocols, and material lists for scientific instruments should be shared, accessible, and able to be replicated" by diverse groups of users, including those not usually counted within science-as-usual, whether they identify as citizen scientists or not (Liboiron \& Molloy 2017; Dosemagen et al. 2017). Yet, as researchers have shown (and practitioners have experienced), access to and manipulation of scientific tools has been "outlawed by intellectual property" laws (Ashton 2008; Söderberg 2010; Wylie et al. 2014).

As a technique of privatization, "intellectual property restricts the use of ideas through patents, the expression of ideas through copyrights, and the methods of acquiring ideas through trade secrets" (Whitt 1998, 38). For citizen and accredited scientists working outside of wellfunded institutions, this effectively means that tools, and thus knowledge, cannot circulate outside of well-funded circuits. As historian Eda Kranakis has shown, "how (and in whose interests) patent systems are integrated affects development and the distribution of wealth and power" (Kranakis 2007, 690), resulting in the gentrification of scientific tools and knowledge.

In this context, it is not surprising that some of the earliest work on lay involvement in science and technology development is characterized by struggle and antagonistic relationships (e.g. Illich 1973; Slack 1984; Söderberg 2010). There are, of course, many fronts within citizen, civic, and other scientific endeavors where power relations are being actively contested. This article focuses on intellectual property as one front among many. The struggle around intellectual 
property (IP) and the development of open-source technologies for citizen science within academic institutions is not new (Wylie et al. 2014; Scassa \& Chung 2015). This article builds on this work by foregrounding tactics and strategies in this struggle, grounded in theories of agency, structure, and power.

In particular, this article seeks to highlight power dynamics within the conditions of knowledge for citizen science. In mainstream discussions on citizen science, acknowledgement of asymmetrical power relations, if they exist at all, focus on the conditions under which citizenproduced knowledge is valid (e.g. Cohn 2008). I argue that whether or not citizen scientists seek to change the structures of science-as-usual, structures of power always already define citizen science activities (McQuillan 2014; Riesch \& Potter 2014). These structures include but are not limited to intellectual property systems (Scasa \& Chung 2015). Making power explicit and part of the mainstream conversation about citizen science is one of the goals of this work.

\section{The Case of BabyLegs}

The star of this article is BabyLegs. BabyLegs is an open source device for monitoring marine microplastic pollution by skimming the surface of the water (trawling) and collecting floating plastics. She is also adorable. She has two little legs that kick in the water when she trawls. She is pink. Once, a child at a science expo "mistook" her for a doll and wandered off with her. BabyLegs' aesthetic and gender pronouns are two tactics among others designed to dodge university IP practices that would have privatized her and kept her from circulating to the rural, northern, fishing communities for whom she was designed. BabyLegs is an ideal case study though which to investigate power and agency because while we were successful in making her open source, this success is deeply shaped and even compromised by existing structures of power; I will argue that agency in such contexts is always compromised. Here, following activist researcher Charles Hale, "compromised" agency means acts of resistance are "partly implicated in the very systems of oppression they set out to oppose" $(2006,98)$.

This article has several goals. The first is activist. I outline the various feminist, queer, and legal tactics we used to delegitimize BabyLegs in the eyes of research office administrators that allowed her stay open source. I wish to share these tactics so others can use them and build upon them in their own contexts. A second goal is methodological. "Making and doing" in STS seeks to create change beyond the academic paper or classroom through material interventions (Downey et al. 2016). BabyLegs is a scientific artifact built explicitly to enact politics informed by STS theory. As such, she offers a case study in making and doing. 
The third and final goal concerns theories of agency. I seek to highlight how power dynamics, in the form of IP systems, work in such a way that references to agency in STS literature often fail to capture. Though STS pledges attention to power, ubiquitous references to the agency of humans and non-humans tend to gloss over power structures that no amount of individual or networked agency can influence. Indeed, agency is determined by such structures. I join others in the concern that power needs to be theorized in direct relation to the concept of agency (for example Klienman 1998; Klein \& Kleinman 2002; Braun et al. 2010; Murphy 2017).

This article begins by laying out the scientific politics of Civic Laboratory for Environmental Action Research (CLEAR), where BabyLegs was born, to articulate the stakes of keeping BabyLegs open source for citizen scientists. To set up a theoretical framework to analyze the tactics we used to maneuver BabyLegs through an intellectual property system, I provide a short review of literature on structure, agency, and power as they pertain to existing work on intellectual property. Then, I get to the meat of the matter and tell the story of designing BabyLegs so she could sneak through the research office, detailing design, performative, and legal tactics. The piece concludes with an analysis of working within existing power structures, and argues that all agency is compromised by the power structures within which agency is exercised.

\section{Laboratory Politics}

Civic Laboratory for Environmental Action Research (CLEAR) is a feminist, decolonial, marine science laboratory that studies plastic pollution in Newfoundland and Labrador, in northeastern Canada. CLEAR's work is informed by the feminist value of equity, whether we are ordering supplies or building scientific instruments. Feminist labs like CLEAR "are not merely bringing more women and trans scientist-inventors into science-as-usual. They prioritize equity rather than equality, recognizing that when people start from fundamentally different social, economic, educational, and political positions, treating everyone the same [equally] does not overcome those differences. In doing so, they transform science in terms of how research priorities are chosen and articulated, what kinds of knowledge [are] considered valid, and, of course, how scientific tools are made and distributed" (Molloy \& Liboiron 2017). At CLEAR, we also strive to decolonize science. Decolonization is a critical response to imperialism and colonialism, and includes questioning the underlying assumptions, motivations, and values taken for granted in Western cultures. This is different than Indigenizing science. Rather than conducting science by and for Indigenous peoples (though there are Indigenous people in the lab), we work to unsettle 
the assumptions of Western technoscience to make room for other ways of doing science, including but not limited to Indigenous sciences. To this end, we emphasize solidarity with the original peoples of Newfoundland and Labrador in our scientific work, and conduct research that aims to keep their ancestral Land healthy and habitable in traditional ways (Tuck \& Yang 2012). In our case, this means paying attention to the plastics in marine food webs.

CLEAR studies marine plastic pollution. Roughly three percent of the United States' oil and natural gas is used to create plastics, either as raw stock material or as the energy source used to fuel the process (US EIA 2015). Despite this small percentage, plastics are one of the most ubiquitous everyday petrochemical products in the world; there is almost no way to obtain food, clothing, shelter, or medical care that is not coated with, wrapped in, or made of plastics, and the amount produced is increasing exponentially (PlasticsEurope 2015). Many of these plastics end up in freshwater and marine environments.

While marine plastics present many environmental issues, such as entangling marine life or reducing oxygen transfer in sediment (Gregory 2009), one of the most pressing problems is plastic ingestion. The problem with ingesting plastics is not the polymer itself. We routinely find plastics in the gizzards and stomachs of healthy animals. The problem with ingestion is chemical. Plastics can absorb up to a million times more synthetic chemicals than are in the surrounding water (Mato 2001). In hot, abrasive, acidic conditions, like those of a stomach, those chemicals will leach out of the plastic and move into an animal's tissues (Rochman 2013). When predators eat these animals, the chemicals transfer to the predator and biomagnify further up the food web (Burreau 2006; Rochman 2013; Tanaka 2013). This means that humans at the top of long aquatic food webs are at high risk of exposure, such as rural people in Newfoundland who rely on fish for sustenance, and particularly Aboriginal communities in Labrador that eat fish and marine mammals. Endocrine disrupting chemicals associated with plastics have been correlated with infertility, recurrent miscarriages, feminization of male fetuses, early-onset puberty, early-onset menopause, obesity, diabetes, cancer, and neurological disorders such as early-onset senility in adults, and reduced brain development in children (vom Saal et al. 2007; Halden 2010: 179-194; Grün and Blumberg 2009: 8; WHO/UNEP 2013). Because endocrine disrupting compounds have greater effects during crucial windows in human development, they also disproportionately affect fetuses, children, and women (WHO/UNEP 2013). This uneven burden is what makes plastic pollution an equity issue. 


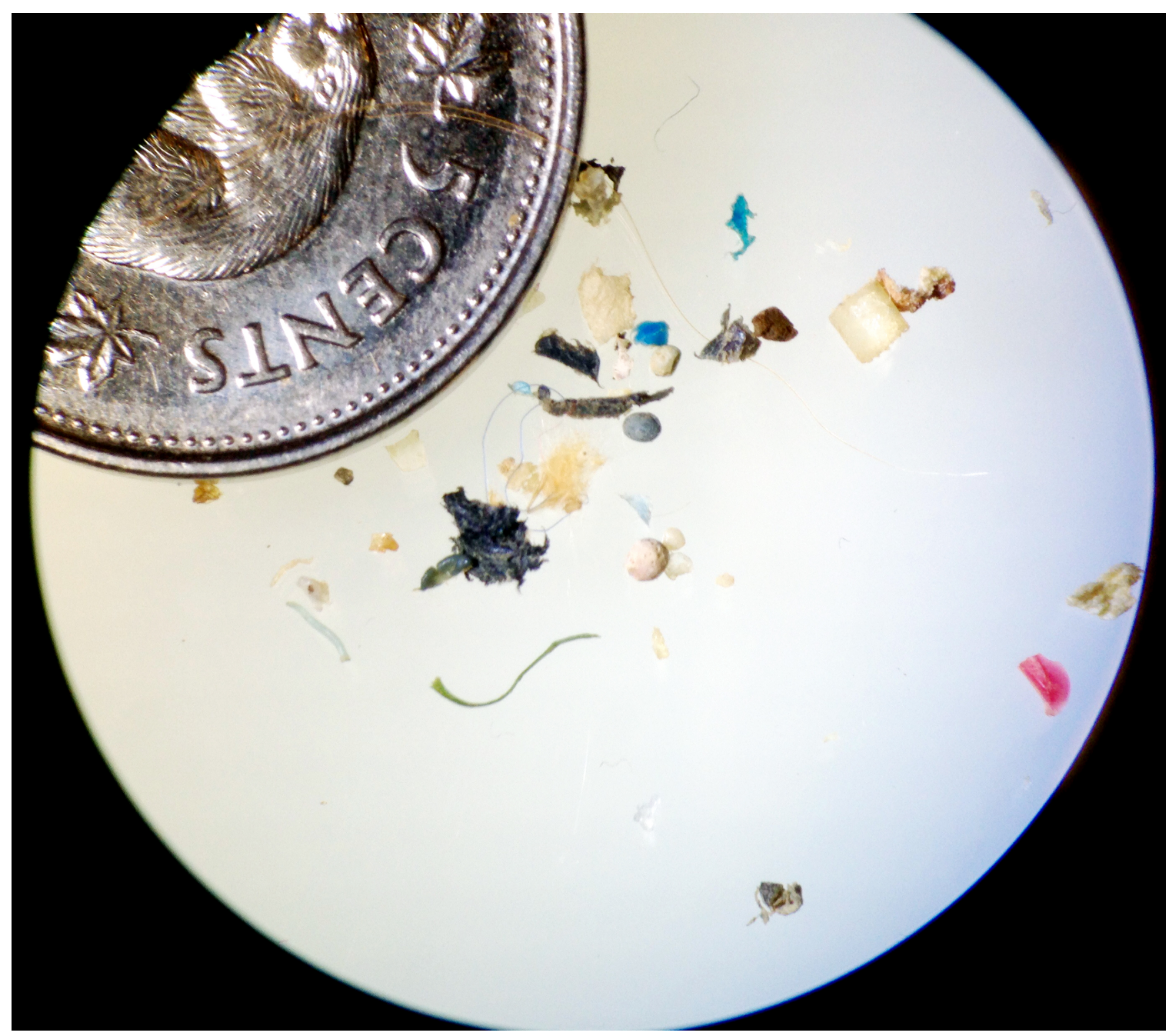

Image 1: Microplastics.

The vast majority of floating marine plastics-93\%— are less than five millimeters in size (Eriksen 2014). They are called microplastics. Most microplastics are formed when larger items fragment into smaller pieces, though some plastics are already tiny, such as microbeads used as exfoliants in personal care products (Napper et al. 2015). The result is a smog of tiny petrochemical-derived plastics in oceans and waterways (Eriksen 2015; Liboiron 2016a). To monitor a smog, whether it is in the food web or in the water, we need special instruments. 


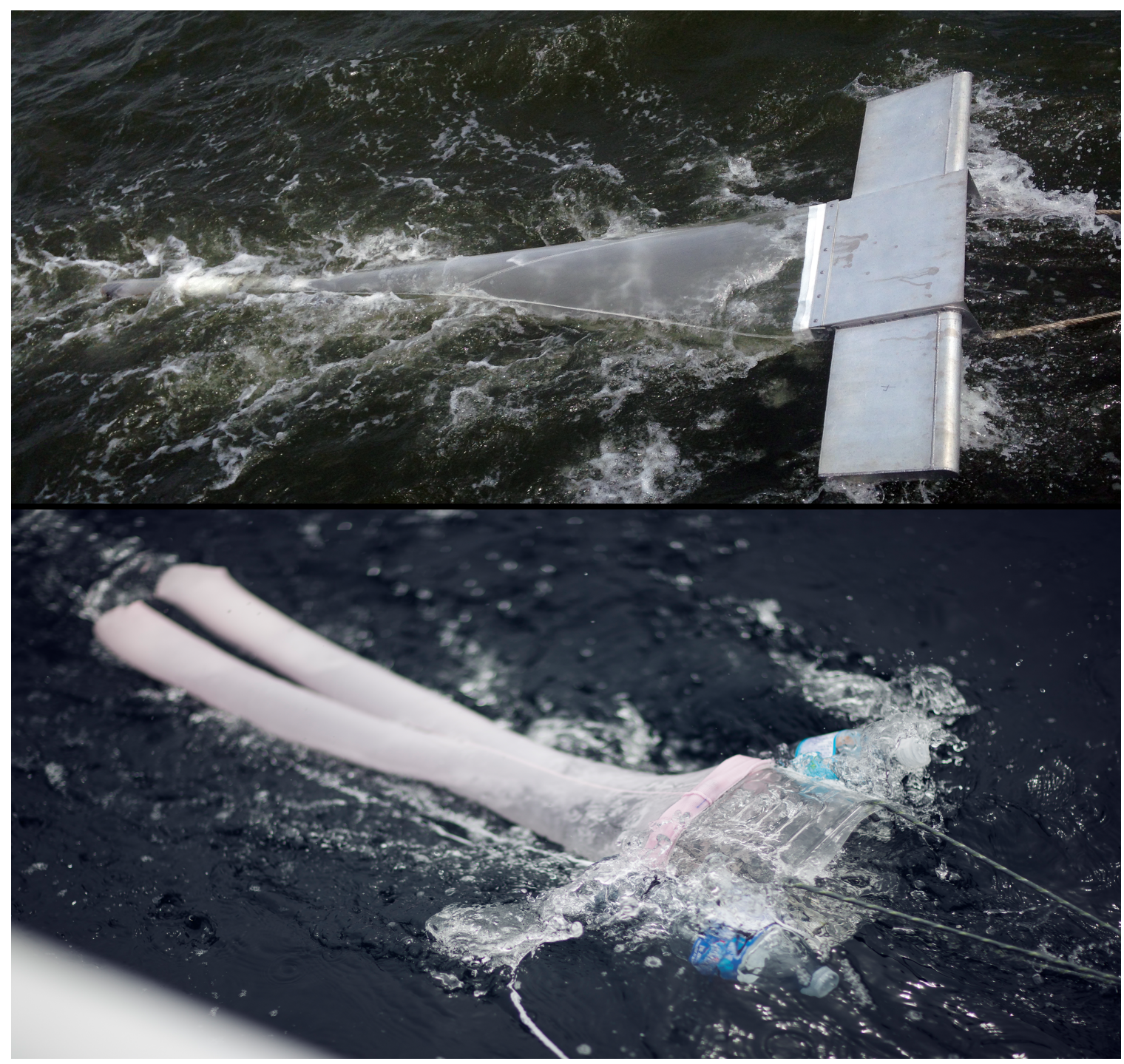

Image 2: BabyLegs vs Manta Trawl.

CLEAR has guidelines for building equitable scientific instruments. We assume that users will be rural and Aboriginal people in Newfoundland and Labrador who have research questions and a right to answer them. Our guidelines are: 1) the technology's design and protocols must be open source and available online; 2 ) the device must be useable without specialized training; 3 ) supplies to build the instrument should cost under $\$ 50 ; 4)$ it must be made with supplies you can buy in rural Newfoundland communities that often have a single general store; 5) instruments 
must be repairable, hackable, and easy to maintain; and 6) devices should not be made of plastics (CLEAR 2017; Liboiron 2016b).

BabyLegs is a technology that follows most of these guidelines (we gave up creating a plastic-free device to ensure costs stayed low, for example). BabyLegs is made of nylon baby tights for a net, a plastic container for a body, a plumber's clamp to attach the tights to the body, and some rope to tow her in the water. These supplies can be found in rural Newfoundland general stores. As water passes through the mouth of the trawl, any floating plastics gather in a fine mesh net, which are then put into sample containers and brought back to the laboratory (or kitchen) for analysis. She costs around $\$ 12$ to make. The standard scientific tool for surface trawling is the manta trawl, which costs $\$ 3,500$ USD and must be made-to-order from a few places in the world. While BabyLegs collects smaller samples than a manta trawl, she is also more versatile; while the manta trawl has to be towed behind a fair-sized, motorized boat, BabyLegs can be towed behind surfboards and canoes as well as motorized boats, used by hand along wharfs, and tied off in streams from bridges or trees (CLEAR 2015). In short, BabyLegs is a placebased technology designed specifically for rural Newfoundland and Labrador citizen scientists.

But BabyLegs' secondary and unanticipated audience is the research office at my university - specifically, the technology transfer department. BabyLegs was invented at Memorial University of Newfoundland, which, like nearly all universities, has an intellectual property (IP) system where the university has the automatic ability to own, privatize, and commercialize anything employees and students invent. University technology transfer offices are also characterized by an institutional culture that believes privatization followed by commercialization is the best, and often only, way to disseminate technology. BabyLegs was built to resist these cultures and practices. However, BabyLegs is just one pair of tights in a wider power structure, and it is this structure that I will turn to next.

\section{Structure, Agency, Power}

BabyLegs looks like a sexy, non-human actant. It's probably the tights. But my journey through the university's IP system did not highlight the capacity of BabyLegs to influence networks as an actant, though she was designed to do just that. My experiences line up with what Daniel Kleinman and other researchers have identified as a "limitation of actor network and social worlds approaches [in] their virtually exclusive emphasis on processes of construction. Active agents are always constructing their worlds in this work. But emphasis on construction turns our gaze away from the effects of the already constructed attributes of the world in which science is 
practiced" (Kleinman 1998, 288). In short, "emphasis on agency has led analysts to ignore or underplay the constraints placed on agents in their efforts to act" (Kleinman 1998, 288). The story of BabyLegs will be told as a series of tactics used to navigate an IP system, and as such there is a temptation to focus on agency as the main analytic. Yet, I want to use BabyLegs to "study up" (Nader 1972) and consider structures of power in IP systems, the ways in which "the situation is shaped from above rather than constructed form below" (Burawoy 1991, 276). This is important because while agency is ubiquitous in STS discourse, the character of different agencies is rarely articulated. I do not have an issue with concepts of agency or actor network theory-I believe in using things when they are useful, and often times these terms are useful. However, there is a need to nuance some of the ambivalences, compromises, and other uneven characteristics at play in agency. In particular, I want to trouble the tendency in STS and activist work to understand agency and action as inherently good. For that, I find theories of structure useful.

Structure is a way to describe asymmetrical power relations that constrain and texture agency. Daniel Lee Kleinman, whose work I lean on heavily for its linking of IP and power, defines structure as that which constitutes, "specific formal and informal, explicit and implicit 'rules of play,' which establish distinctive resource distributions, capacities, and incapacities and define specific constraints and opportunities for actors depending on their structural location. Power and its operation are then understood within this structural context" $(1998,298)$. These rules of play manifest in norms, practices, and material infrastructure, and dictate not only what is normal and acceptable, but also what can make sense and be considered legitimate knowledge in science and technology development (Harding 2016; Kuhn 1970). Crucially, structures are neither universal nor evenly distributed (Foucault 2002/1970), but nor are they "more or less precariously structured relations" (Law 1991, 170). Structures have great inertia and are difficult to shift (Hughes 1987).

Yet structures are not immutable, stable as they may be. Klienman argues that "if we accept that structures are always in the process of (re)constitution, it is a matter of investigating specific historical cases to trace when stable structures are constraining and when and to what extent practices alter structures. We cannot assume either that the world is overwhelmingly constraining or that it is easily manipulable" $(1998,308)$. Intellectual property systems are one such case. 


\section{The Power of Intellectual Property}

As a system, intellectual property (IP) "restricts the use of ideas through patents, the expression of ideas through copyrights, and the methods of acquiring ideas through trade secrets" (Whitt 1998, 38). Initially, the impetus for establishing private scientific property was a way to support scientific communities that had been devastated during the First World War and attendant economic crises (Miller 2008), though privatizing intellectual products predates scientific IP (O'Reagan 2017; Kranakis 2007; Lubar 1991). Patenting is a legal grant for the creator of an invention or process to solely make, use, and sell that invention. In universities, patenting has been increasing since the 1980s (Mowery 2001). In a review of US higher education trade publications, Kleinman and Osley-Thomas (2014) found broad support for intellectual property in universities, and few cases of opposition. At the same time, research by Lave, Mirowski and Randalls found that of 46 research organizations that used material transfer agreements (MTAs) in their research, "75 percent of them reported having at least one MTA negotiation break down within the past year. In Belgium, 60 percent of researchers reported abandoning projects because of problems with intellectual property restrictions on research tools" (Lave et al. 2010, 667; Rodriguez et al. 2007). Other research on privatizing intellectual property within academia and industry has shown that privatization slows innovation rather than supports it (Dworkin 1987; Hope 2009; Heller \& Eisenberg 1998; Heller 2010). Thus, despite wide support on discursive and ideational levels, in practice there are widespread issues with privatization in research settings.

In most literature, IP is described as a system defined by rule-like practices (Lentacker 2010). It not only organizes access, but also operates "as an institute: it specifies a set of rules and opportunities and constraints" (Kleinman 1998, 301). Others have explicitly described IP as "tools of power and control" (Kranakis 2007, 689) linking it directly to "establishing hegemony... over other ways of knowing" (Kleinman 1998, 288; Whitt 1998; Lave 2010). This is particularly true in cases where objects, living beings, and knowledge that already circulate widely are privatized, such as in biopiracy (Merson 2000; Mgbeoji 2014; Foster 2016). In these cases, agency is so highly constrained that using it as an analytical framework misses how power operates, even when groups are successful at navigating IP to retain some kind of ownership over local knowledge or beings. For instance, Indigenous groups have to use colonial and Western concepts of ownership to keep "their" knowledge (Foster 2016).

Power operates within IP systems by adjusting, sometimes violently, relations between groups (Hayden 2007); by "explicit deconstruction and crossing of the borders between factories, laboratories, law offices, and courtrooms" (da Costa Marques 2005, 149) to form a hybrid space where the norms and rules of one space colonize the others; by entrenching Western, colonial, 
and/or sexist values in social relations (Foster 2016); and as a form of disciplining subjects (Kranakis 2007; da Costa Marques 2005; Söderberg 2010). Most importantly for this case, some of these manifestations of power allow certain things to make sense while others do not (Foucault 2002/1970), and this sense-making maps onto dominant values that are not necessarily in the best interest of individuals or groups (Foucault 2002/1973). Certain values and worldviews structure intellectual property systems, including:

[t]he epistemological assumptions around notions of stable borders and discovery [which] are associated with the idea of the "primacy of the origin," which invokes the precedence, priority, predominance, preference, prerogative, privilege, right-of-way, seniority, supremacy of the original over the copy, of the model over the imitated (da Costa Marques 2005, 139).

These values are grounded in hyper-individualism, stable borders, and private property, the hallmarks of Western culture and colonialism (Bang 2014; Moreton-Robinson 2015). Patenting and copyright have been described as forms of "enclosure" (e.g. Söderberg 2010, 162), the imperial act of drawing boundaries around formerly common land so it can no longer be shared (Goldstein 2013). Crucially, studies on colonialism have shown how making private property "is a structure rather than an event" (Wolfe 1999). While it might be enacted in moments, it is grounded in much wider and older structures of Western value systems. This is also how IP exceeds infrastructures and is part of power structures; while the built environment certainly allows IP regimes to reproduce themselves, the ability for some infrastructures to succeed at reproduction comes from less material sources (Foucault 2002/1973).

Nearly all cases in STS literature and history on IP investigate at how scientists and inventors seek patent protection, rather than avoid it. BabyLegs, on the other hand, is an example of coordinated practices resisting IP in the academy (cf Wylie et al. 2014). As such, she is a counter story that opens up other ways of studying "exactly how neoliberal theories of society are transforming technoscience" (Lave 2010, 670) and how "the ways in which the demands of intellectual property regimes ... can affect scientists' decisions and practices" (Kleinman 1998, 303), particularly within a feminist, decolonial marine science context. As such, the case of BabyLegs aligns with arguments that innovation is often a result of antagonistic relationships in situations of asymmetrical power relations where "users innovate precisely in order to overthrow the material practices upon which intellectual property law is founded" (Söderberg 2010, 151; also Negri 1996; Holloway 1992). That is, designers design against dominant values such as 
privatization, individualist subjectivities, and discovery (primacy of the origin) as part of political struggle.

Innovation in design, though, is not enough. As de Costa Marques asks, "in the context of the increasing investments in the framing of intellectual property, can postcolonial deconstructions of the Western concepts of discovery and authorship be relied upon to challenge relations of dominance?" (2000, 140). For BabyLegs, the answer is no. While she "successfully" wends through the IP system and emerges open and free, relations of dominance are only deferred, not shifted, challenged, or changed. This does not mean BabyLegs is futile. Operating as

a feminist, decolonial, marine science laboratory in a sexist, colonial university setting (Gutiérrez y Muhs et al. 2012) is a deeply political act that reinforces CLEAR's ethics and enacts important lessons for the twenty or so members of the lab. It is also a way to understand the practices of dominant systems so they might be maneuvered with more ease in the future. Moreover, demanding that all political acts be revolutionary is cheeky. Often, "weapons of the weak," made up of "foot-dragging, evasion, false compliance, pilfering, feigned ignorance, slander, and sabotage" (Scott 1985, xvi) are all that are available, and are meaningful acts of resistance in and of themselves.

These acts of ethics, learning, and resistance are tactical. De Certeau (1998) differentiates between strategies and tactics; tactics are adjustments, appropriations, and manipulations of objects, while "strategies are expression of structures of power exerted by institutions (broadly construed) to describe and prescribe courses of action" (DiSalvo 2009, 52), such as the mandate to patent. This following section will outline how BabyLegs was invented, and how designs and representations were tactically employed to resist the wider university strategy of privatization.

\section{BabyLegs: The Saga}

BabyLegs began as a way to see mircobeads in sewage outflows. As a recent transplant to Newfoundland, I was looking to learn about my new home from a pollution perspective. Rural communities in the province use septic tanks or sewage outflows that empty into the Atlantic Ocean. I wanted to catch some sewage and root around in it for tiny, hard-to-see, polyethylene beads found in many toothpastes and face washes. To do this, I needed a fine-mesh net and a way to steer water into the net. I stretched a pair of white toddler tights over an empty juice container and pinched the tights taunt over the container with my fingers to form a scoop. 


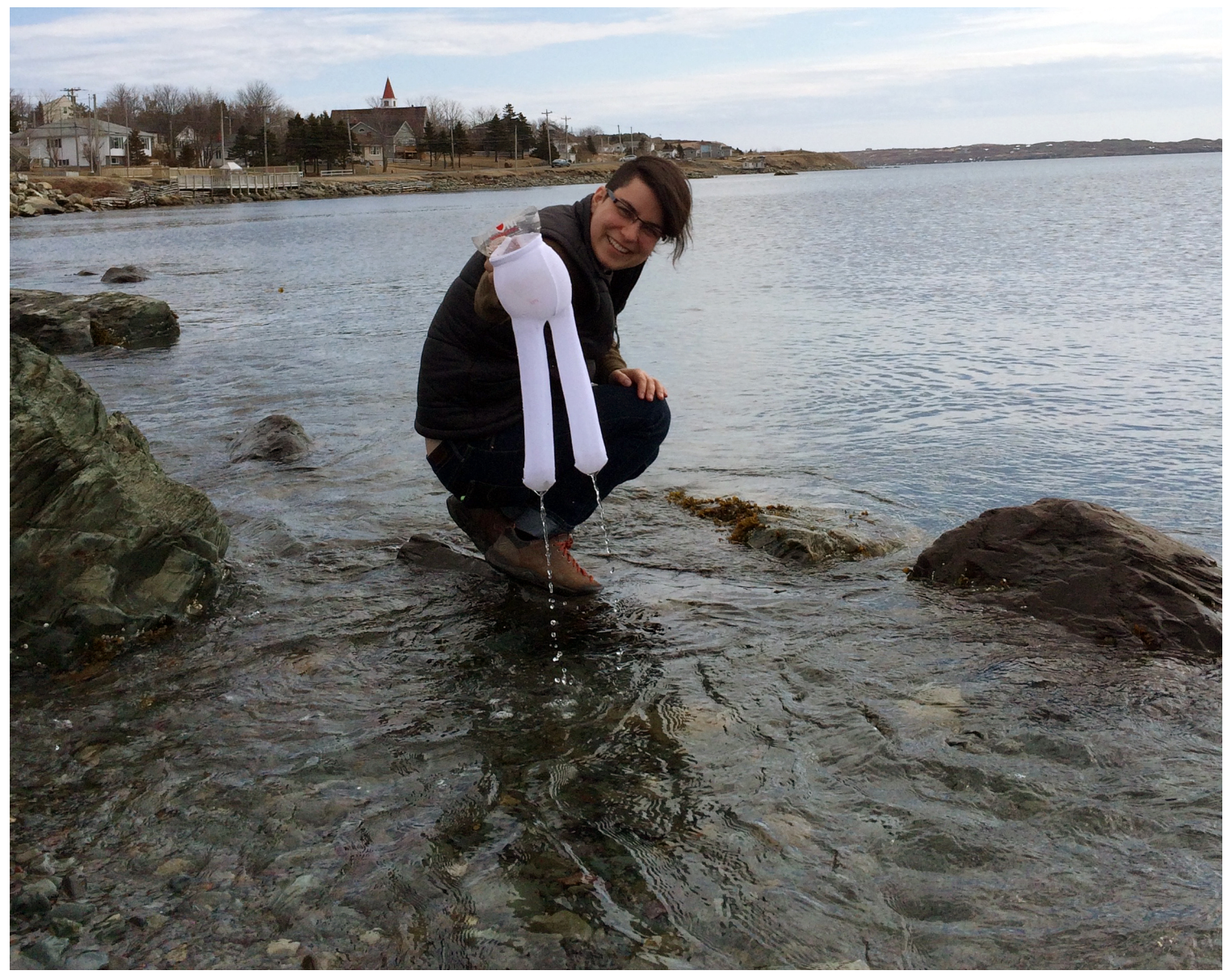

Image 3: BabyLegs at the sewage outflow.

It worked wonderfully. Within minutes of being introduced to a rural sewage outflow, BabyLeg's toes filled with shit and debris. I slid the tights into a plastic bag for later analysis in the lab, where I found microplastics: cigarette butts, threads likely from a kitchen scrub brush, and nylon lint likely from a washing machine, though no microbeads. I was surprised at how well the tights worked, and decided to develop the make-shift scoop-net into a full trawl prototype for towing behind a boat. I added a plumber's clamp to keep the tights on the container, a rope rigging to attach the trawl to a boat, pontoons to keep her steady in waves, and a square mouth to better calculate the volume of water passing through the device.

I had made a new scientific instrument. According to my collective agreement, this meant I had to disclose the technology to our research office. The collective agreement states: 
The researcher shall notify his or her Administrative Head in writing of the development or creation of any intellectual property that has potential for commercial exploitation. [This is called disclosure.] Within thirty (30) days of the date that the Administrative Head was so notified, the University shall determine whether it will participate in the commercial exploitation and shall notify the researcher in writing of its determination. If no determination is made within that period, the researcher is free to pursue commercialization without the University's participation. ... This patent protection shall be pursued in the name of the researcher who is the inventor, discoverer, or creator. The cost involved in this process shall be paid by the University. The researcher shall provide full co-operation and assistance in the preparation of the patent application (Memorial University of Newfoundland 2015).

These policies are designed to protect graduate students, researchers, and extra-academic partners in multi-party disputes over jointly-created IP. However, these practices of protection assume that privatization followed by commercialization (which are usually conflated as two steps in the same process rather than two separate processes), is not only the best way, but the only way to disseminate technological inventions. As a case in point, "technology transfer" in policy and industry documents usually refers exclusively to "transferring discoveries and innovations resulting from university research to the commercial sector" (e.g. Bastani et al. 2015), and even Memorial University's collective agreement assumes that the inventor will commercialize their invention if the university opts out. Yet there are many other licenses that allow new technology to be free and accessible to a wide range of potential users through circulation..$^{2}$ The university IP paradigm presents a problem as all institutional routes lead to privatization.

To avoid this, I set out to make a trawl made with toddler tights into an icon of adorable femininity, childishness, silliness, and sexy queerness in order to discredit her in the eyes of the research office that adjudicates technologies to see if they will be taken up by the university for privatization and development. First, I switched out BabyLeg's square body for a Pom Wonderful bottle, which has a crimped waist and hourglass figure. Her regular tights were replaced with toddler tights that had hearts on them. Rather than providing a schematic diagram of the device

2 There are several titling and licensing practices that produce value through sharing: public domain, Creative Commons, Copy Left, and open hardware licenses such as CERN (European Organization for Nuclear Research) and TAPR (Tuscon Amateur Packet Radio), among others. These are legally binding licenses for sharing. Some of these allow commercialization (introducing goods to the market) without privatization (making that and other rights exclusive). 
for disclosure, I took BabyLegs to a department store portrait studio and had her baby portrait taken; in a stroke of fabulous politics, the older woman running the studio crossed BabyLegs' legs without comment before snapping the picture. BabyLegs was anthropomorphized (DiSalvo \& Gemperle 2003) as girly and childlike, but also womanly and sexy.
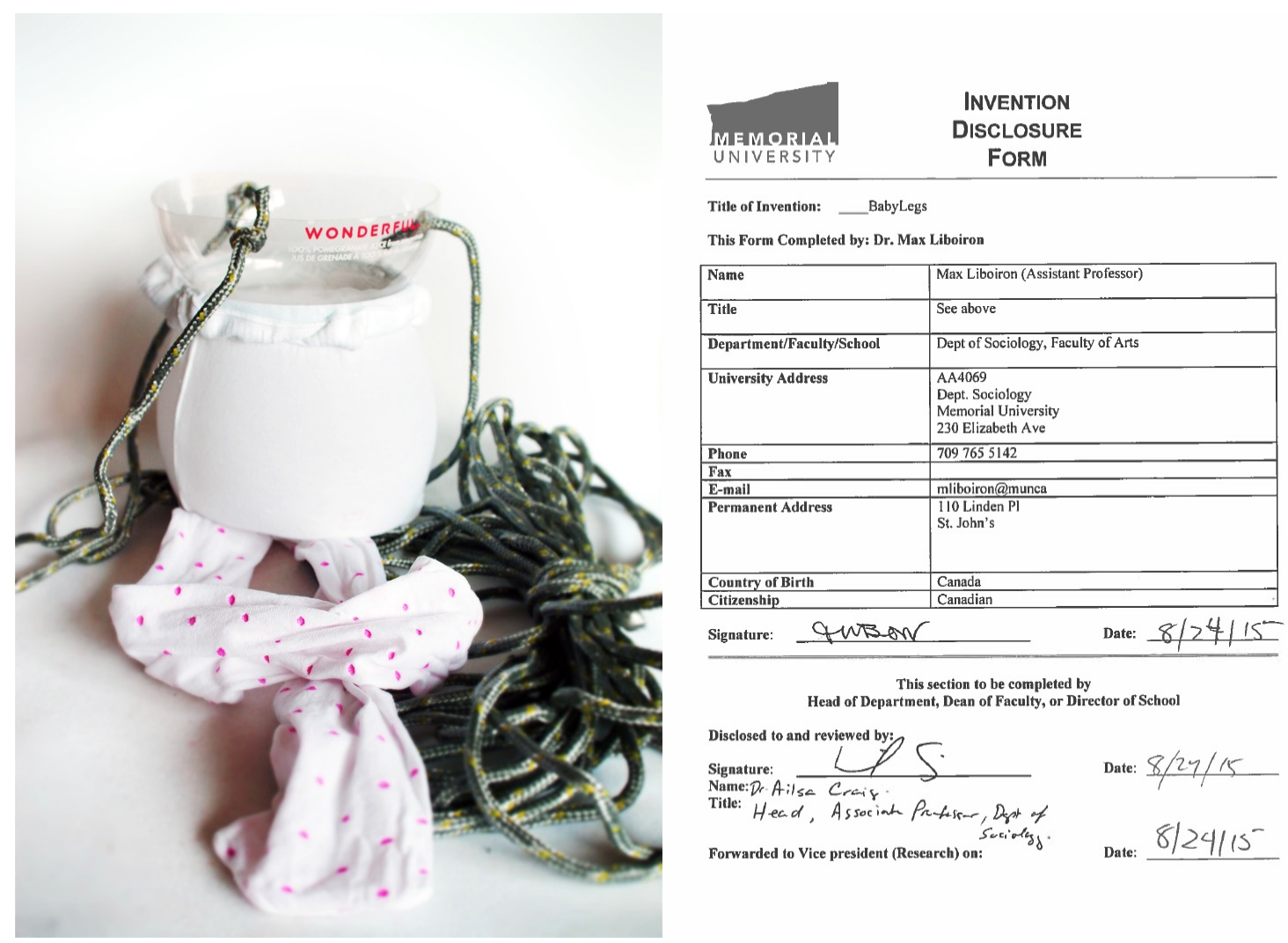

Image 4: BabyLegs disclosure image.

In the disclosure form, words like "cheap," "fabulous," and "panty hose" appeared regularly, and both myself and my department head (who had to write the cover letter) referred to BabyLegs as "she" and "her" throughout.

The final tactic was to include one other disclosure at the same time as BabyLegs'. In my feminist technologies course, some students had invented another surface trawl called the Plastic Eating Nautical Instrument System, or P.E.N.I.S. The P.E.N.I.S. was shaped like a phallus with a detachable meatus, designed as a "stiff funnel that collects floating marine plastics" (Quigley et al. 
2015). Yet, despite its charm, "[t]he main problem with the P.E.N.I.S. is that the holes freeze in the winter. It has not detected any plastics to date" (Quigley et al. 2015). Since the P.E.N.I.S. didn't work, we did not have to disclose it, but the tactical advantage of sending BabyLegs into the research office accompanied by P.E.N.I.S. was too great to ignore.

After we complied this sexy paperwork and disclosed the two trawls, we heard nothing from the research office for thirty days. According to the collective agreement, that meant that the university had lost its window to claim BabyLegs for privatization and commercial exploitation.

\section{Structures of Interpretation}

In their analysis of structure in the social construction of technology, Klein and Kleinman (2002) write that, "[a] decisive factor in the development of artifacts is frequently cultural resources [... and that] the position of relevant social groups interested in shaping the character of a given technology will be enhanced to the extent that they can draw on deeply institutionalized myths in making their case" $(43,44)$. My myths of choice originated in dominant gender norms. Judy Wajcman (2010), Ruth Oldenziel (1999), Ellen van Oost (2004), and many others in feminist science and technology studies have written about the association of masculinity with technology, and the masculinity of engineering culture in particular. Most of the engineering activities at Memorial University, including the activities in the technology transfer office, are geared towards oil extraction and commercial fishing, both of which are additionally (and dynamically) masculinized in relation to technology and commercial values (Power 2005, 2008). I counted on this perfect storm of machismo and commercial imperative to put BabyLegs in hyperfeminine drag.

Catelijne Coopmans has written about the role of images and appearances in producing value in IP systems (2010). While Coopmans' case study is about inventors using appearance to gain patents for their inventions, the same tactics hold to discredit the technology. Feminizing BabyLegs specifically used gender norms to delegitimize her (and me) in the eyes of the research office administrators. Legitimization is "a generalized perception or assumption that actions of an entity are desirable, proper, or appropriate within some socially constructed system of norms, values, beliefs and definitions" (Suchman 1995, 574) and a "practice is considered legitimate when it fits easily within established cultural frames" (Scott 1995, 45; quoted in Kleinman \& OsleyThomas 2014, 3). This includes gender norms. My tactics were designed to breech these norms and offer a specific interpretation of the technology to a particular social group (Bijker 1997). 


\section{Tactics from a Lawyer}

I've told the story of BabyLeg's disclosure as if she was invented, disclosed, and escaped. Yet I disclosed BabyLegs at least three times. After the first thirty days went by, I assumed the ordeal was over. But when I submitted a grant proposal several months later, an administrator in the technology transfer office noticed that I had listed five technology disclosures on my CV. He emailed to say he was "very interested" in them, and that there was no disclosure on record for either my solo technology, BabyLegs, or the four student technologies I had disclosed since then, including P.E.N.I.S. Perhaps we were so well delegitimized that no record existed of our dismissal. One can hope.

A flurry of activity followed, including emails to department heads, union representatives, and students. My union representative advised me to re-disclose all technologies. We were not sure whether this meant the new disclosures made them available for privatization from the university, especially since BabyLegs had grown up considerably since her last disclosure and was now a validated and experienced trawl. She had been to the Arctic and Antarctic Oceans. There were fancy pictures. I was deeply concerned that BabyLegs would be understood as a desirable technology and repossessed.

Then followed many meetings with administrators and lawyers. We spent most of the time determining the legal standing of the disclosed technologies to see whether the university had claim to them. At first, they thought I was confused and would much prefer to privatize the technologies for commercial aims, no matter how small, even if the university were not involved. They offered to help me figure out how to remove the unfortunate open source Creative Commons licenses my students and I had placed on the technologies. In the end, we decided that the technologies could remain open source. My university tends not to patent student technologies. In the case of BabyLegs, it seemed that the Creative Commons license I had put on her after the initial disclosure was legally valid, or at least legally sticky.

Then something odd happened. The university lawyer (the only women in the meetings besides myself) began to help me. I was surprised. She outlined possible tactics for maneuvering administrative and legal structures for future endeavors:

- Do not disclose. While our collective agreement states that we need to disclose inventions, there are two loopholes. One is the tyranny of common practice: most employees do not disclose. In a culture where this is normal, neglecting to disclose "might be" defensible. Secondly, and more concretely, the collective agreement at Memorial states that researchers 
shall disclose "the development or creation of any intellectual property that has potential for commercial exploitation." If I did not think the IP had potential for commercial exploitationwhich is not defined - then legally I did not have to disclose.

- Do not make commercially viable technology. For the research office, "viable" means that it can make back the considerable cost of obtaining a patent. Several of my students aimed to make their technologies cheap, transparent (meaning it was fairly obvious how it was made), and made of materials that included other patented items (like coffee filters).

- Disclose publicly. If you post your plans on a website, present them at a conference, or publish them in a journal, they are no longer private, and thus prevent a problem to privatization. The head administrator said that researchers accidentally disclose publicly all the time. Whoops!

- Do not sign required forms. Inventors will have to sign forms to hand over their IP rights. The lawyers said not to sign them. Alternatively, they recommended taking a long time to sign forms as a way to stretch out timelines and make them less efficient. I have begun filling out the wrong forms to add even more time to this process.

- Be difficult. One administrator noted that the process of creating jointly-owned patents requires a "coalition of cooperation." If one (or more) people are not cooperating, the process falls apart.

- Invent with others, many others. Joint IP is more difficult to deal with because figuring out who has what original input into the object, and how much, and thus who must be involved in transferring IP and awarding payments is complicated, even prohibitively so. The more people that have been involved as co-inventors, the more complicated it becomes. Part of the reason is that IP is based on individualism, and if there are multiple people doing multiple tasks it becomes difficult to atomize which tasks are "assistant" tasks and which are "originating" tasks during the process of invention. This is amplified if some of those people are from outside of the university or outside the country given national differences in IP norms (Kranakis 2007, Merelis 2012).

- Work with students. Students are difficult to organize, particularly over the timelines that patenting can entail. As one administrator put it, "[t]hey disappear all the time! Especially after graduation." At Memorial, there is also extra scrutiny of student-faculty shared IP because administration aims to protect students from having their IP controlled unfairly by faculty. Often, they just do not touch it. 
- Use Creative Commons and other open licenses early and often. These licenses are quasilegal and it is not always clear where and when they are legally binding. Even if they are not binding in some areas, they still must be shifted through, which takes time and money.

- Do not invent technology-invent processes. While IP is supposed to cover proprietary technology and processes, the focus is almost exclusively on technology. CLEAR creates citizen scientific protocols as well instruments, and none of our protocols have ever been scrutinized, or even noticed. They certainly have not been disclosed (see point \#1).

I hope these, as well as BabyLegs' aesthetic tactics, are useful for others in similar situations.

To be clear, the case of BabyLegs does not provide a theory of change. It only provides a theory of maneuverability. All of the tactics described here are what James Scott calls "weapons of the weak" (1985), tactics of resistance exercised by "foot-dragging, evasion, false compliance, pilfering, feigned ignorance, slander, and sabotage" (xvi). Such tactics dodge and defer power structures, rather than alter them. While BabyLegs might sound like a success story, this success has to be situated and understood as limited from a perspective where challenging the cultural tenants of IP such as individualism and private property are the end goals of the laboratory. Moreover, BabyLegs is only a momentary respite. CLEAR hasn't invented anything since 2015 because we have a new grant co-funded by Irving Shipbuilding Inc., which has a particularly aggressive IP policy that goes beyond Memorial University of Newfoundland's policies. The problem with structures is that instances where power manifest keep on coming. In light of our new IP agreement, our tactic is to stop inventing. The other available tactic is to not take the grant, and let the students it supports leave university or get a loan. This is the extent of my ability as an agent to influence anything. It is the illusion of choice.

\section{Compromise}

Some social movement stories are framed as seeking "a seat at the table." As a director of a feminist and decolonial laboratory, I did not want a seat at the table of intellectual property. That table is fucked up. In a perfect world, BabyLegs would have pounded her fists on the table, flipped the table, and burned the table down. But all we could do was slip out of the side entrance and hope those at the table did not call on us to sit down and mind our manners. As activist-anthropologist Charles Hales has pointed out, action-oriented researchers are "inevitably drawn into the compromised conditions of the political process" that often put us between a rock 
and a hard place (Hale 2006, 98, emphasis added). To build open source technology in the university, I must engage with privatization. I can try to resist or deviate from it, but privatization is given. So is commercialization. So is sexism. Those tables are set.

It is not only the structures that are compromised. So too, are tactics. I engaged in a kind of strategic essentialism (Spivak 1987), where difference and heterogeneity-two of the hallmarks of intersectional feminism that I firmly believe in-are glossed over so that identity categories can do political work. Feminist scholars such as Claire Colebrook have argued that using essentialism as a tactic is different than essentialism per se as, "we need to posit the essence of the feminine or woman for political reasons. And this is where Certeau's notion of tactic is of most help; for it neither reduces being to its representation, nor asserts the presence of some prerepresentational essence. A tactic occurs between the notion of an imposed strategy and its ground or essence" (Colebrook 2001, 567). Despite these theoretical assurances, it still feels dirty as a feminist to lead with gender roles I wouldn't be caught dead wearing. Using essentialist, sexist representations of femininity to accomplish feminist ends seems a fitting example of agental compromise.

Compromise has consequences. One of the unintended consequences of leveraging gender roles in Babylegs' construction is that while children and women at public science events pick her up and appear to feel comfortable around her, fishermen won't touch her. As cold water cowboys (Hallett 2016), fishermen are reluctant to handle a doll-trawl. Fish harvesters, nearly all of whom are men, are some of the main people CLEAR makes technology for and works with to monitor plastics in food webs. Once again, structure gets the last word, as we do not get to choose when to stop leveraging gender roles. They just keep on gender rolling.

There is no place of purity from which to launch activist politics (Gedalof 2005; Hale 2006; Shotwell 2016). Working within and against systems we have already identified as unethical, colonial, sexist, or otherwise oppressive means that we often have to use the language, myths, tools, legal systems, and funding of oppressors to resist these systems (Lorde 1984; Hale 2006). Charles Hales writes that activists and others resisting power structures,

regularly engage in subversion, imbue the dominant with alternative meanings, find room for maneuver, and in so doing, bring about consequences that are quite different than the ones that the dominant actors have in mind. Yet these conditions also impose formidable constraints, which analysts caught up in the "romance of resistance" often tend to gloss over or minimize (2006, 111; cf DiSalvo 2014). 
I follow Hale in arguing that political expressions and actions are also fundamentally compromised, where some aspect of our struggles and designs reinforce and reproduce the structures of power and essentialism they are designed to resist (Sandoval 2000; Rowe \& Tuck 2017). These ambivalences (Woolgar \& Cooper 1999) are especially obvious when using technology to do political work on the ground (Hale 2006). Here, sexism is used for feminist ends; the Open Science Hardware movement of which BabyLegs is a participant works to change how scientific instruments are created and for whom, but reinforces science as a dominant mode of knowledge; and despite my insistence and intent to do science in feminist and decolonial modes, the story of BabyLegs maps effortlessly onto masculinist and colonial myths of heroism, individualism, and of empowerment via access (Fristch 2016). These are the textures of agency.

This thematic collection is about what STS can bring to citizen science practices, particularly those caught in petrochemical structures. One small goal of this text is to offer tactics to circumvent IP systems based in STS theory. It is a practical example of how to take Langdon Winner's assertion (1980) that "artifacts have politics" and use that insight to intentionally to build specific politics into our artifacts (Knobel \& Bowker 2011). The wider, theoretical goal is to encourage both STS and citizen science practitioners to think about power, structure, and agency, recognizing that because of the structural nature of power, agency in on-the-ground citizen science projects is going to be compromised. Agency is always compromised. This recognition lets us be more intentional in how we might compromise.

\section{Author Biography}

Dr. Max Liboiron is an Assistant Professor in Geography at Memorial University of Newfoundland and Director of the Civic Laboratory for Environmental Action Research (CLEAR), a feminist, decolonial, marine science laboratory. Liboiron's research bridges the physical and social sciences in its investigation of how marine plastics are represented in science and how these methods of representation relate to action. Liboiron is managing editor of Discard Studies, a member of the Endocrine Disruptors Action Group (EDAction), and a co-organizer for the Gathering for Open Science Hardware (GOSH).

\section{Acknowledgements}

I would like to respectfully acknowledge the Land within which BabyLegs was created and this text was written as the ancestral homelands of the Beothuk, and the island of Newfoundland as 
the ancestral homelands of the Mi'kmaq and Beothuk. I would also like to recognize the Inuit of Nunatsiavut and NunatuKavut and the Innu of Nitassinan, and their ancestors, as the original people of Labrador. I would like to thank: A. Craig for support during the IP negotiations and for rides to beta test BabyLegs; the administrators in the research office at our university for the hours and effort they put into my case, and especially for some of the content of this article; members of CLEAR for input on this draft; Nick Shapiro and Sara Wylie for putting together this thematic collection, as well as the editors at ESTS and anonymous reviewers who strengthened the article considerably. Peer review is an intellectual gift, and it is deeply appreciated. This work is supported by SSHRC Insight Development Grant \#430-2015-00413, "Action Research Methodologies for the Anthropocene."

\section{References}

Ashton, Daniel. 2008. "Policy, productivity, passion and piracy: Drawing lines around innovation in a knowledge-based economy." eSharp 12: 1-24.

Bang, Megan, L. Curley, A. Kessel, A. Marin, E. Suzukovich III, and G. Strack. 2014. "Muskrat theories, tobacco in the streets, and living Chicago as Indigenous land." Environmental Education Research 20(1): 37-55.

Barad, Karen. 2007. Meeting the universe halfway: Quantum physics and the entanglement of matter and meaning. Durham, NC \& London: Duke university Press.

Bastani, Behfar, E. Mintarno, and D. Fernandez. 2015. "Technology Transfer: Licensing Intellectual Property from Universities to Industry." Fernandez \& Associates, LLP.

Bijker, W. E. 1997. Of bicycles, bakelites, and bulbs: Toward a theory of sociotechnical change. Cambridge, MA: MIT Press.

Braun, Bruce, S. Whatmore, and I. Stengers. 2010. Political matter: Technoscience, democracy, and public life. Minneapolis: University of Minnesota Press.

Burawoy, Michael. 1991. "The extended case method." In Ethnography unbound: Power and resistance in the modern metropolis, edited by M. Burawoy, A. Burton, A. A. Ferguson, K.J. Fox, J. Gamson, N. Gartnell, L. Hurst, C. Kurzman, L. Salzinger, J. Schifman, and S. Ui, 271-87. Berkeley: University of California Press

Burreau, Sven, Y. Zebühr, D. Broman, and R. Ishaq. 2006. "Biomagnification of PBDEs and PCBs in food webs from the Baltic Sea and the northern Atlantic Ocean." Science of the Total Environment 366(2): 659-672. 
CLEAR. 2015. "BabyLegs." Civic Laboratory for Environmental Action Research, May 31. Accessed 9 July 2017. https: / civiclaboratory.nl/2015/05/31/babylegs /

CLEAR. 2017. "CLEAR guidelines for designing equityable scientific tools." Civic Laboratory for Environmental Action Research, April 26. Accessed 9 July 2017. https:/ / civiclaboratory.nl/ 2017/04/26/ clear-guidelines-for-designing-equitable-scientific-tools/

Cohn, Jeffrey P. 2008. "Citizen science: Can volunteers do real research?." AIBS Bulletin 58, (3): 192-197.

Colebrook, Claire. 2001. "Certeau and Foucault: tactics and strategic essentialism." South Atlantic Quarterly 100(2): 543-574.

Coopmans, C. 2010. “'Face value': New medical imaging software in commercial view." Social Studies of Science 41(2):155-176.

Marques, Ivan da Costa. 2005. "Cloning computers: From rights of possession to rights of creation." Science as Culture 14(2):139-160.

De Certeau, Michel, and P. Mayol. 1998. The Practice of Everyday Life. Minneapolis: University of Minnesota Press.

DiSalvo, Carl. 2009. "Design and the Construction of Publics." Design issues 25(1): 48-63.

DiSalvo, Carl. 2014. "Critical making as materializing the politics of design." The Information Society 30(2): 96-105.

DiSalvo, Carl, and F. Gemperle. 2003. "From Seduction to Fulfillment: The Use of Anthropomorphic Form in Design." DPPI '03 Proceedings of the 2003 International Conference on Designing Pleasurable Products and Interfaces, 67-72.

Dosemagen, Shannon, M. Liboiron, and J. Molloy. 2017 "Gathering for Open Science Hardware 2016." Journal of Open Hardware 1(1): 4-8.

Downey, Gary Lee, U. Felt, K. Fortun, Y. Fujigaki, B. Lewenstein, N. Marres, H. Thomas, J. Willinsky, and C. Wu. 2015. "Opening Presidential Plenary: Making and Doing II: The Formation and Ecologies of STS Practitioners," Annual Meeting of the Society for Social Studies of Science, Denver, CO. Accessed January 27, 2016, at http:/ /www.4sonline.org/ meeting/15.

Dworkin, Gerald. 1987. "Commentary: Legal and ethical issues." Science, Technology, \& Human Values 12(1):63-64.

Eriksen, Marcus, L. Lebreton, H. Carson, M. Thiel, C.J. Moore, J.C. Borerro, F. Galgani, P.G. Ryan, and J. Reisser. 2014."Plastic pollution in the world's oceans: more than 5 trillion plastic pieces weighing over 250,000 tons afloat at sea." PloS one 9(12): e111913. 
Eriksen, Marcus. 2015. “Which US City Produced This Horrific Plastic Sample during the SEA Change Expedition?" 5 Gyres. August 9. Accessed 1 July, 2017. http://www.5gyres.org/ blog/posts / 2015 / 8/9/ which-us-city-produced-this-horrific-plastic-sample-during-thesea-change-expedition.

Foster, Laura A. 2016. "Decolonizing Patent Law: Postcolonial Technoscience and Indigenous Knowledge in South Africa." Feminist Formations 28(3):148-173.

Foucault, Michel. 2002/1970. The order of things: An archaeology of the human sciences. Abingdon, UK: Psychology Press.

Foucault, Michel. 2012 / 1973. The birth of the clinic. London: Routledge.

Fritsch, Kelly. 2016. "Accessible." In Keywords for Radicals: The Contested Vocabularly of LateCapitalist Struggle, edited by Kelly Fritsch, C. O'Connor, and A.K. Thompson, 23-28. Chico, CA: AK Press.

Gedalof, Irene. 2005. Against purity: Rethinking identity with Indian and Western feminisms. London: Routledge.

Goldstein, Jesse. 2013. “Terra Economica: Waste and the Production of Enclosed Nature.” Antipode 45 (2): 357-75.

Gregory, Murray. 2009. "Environmental Implications of Plastic Debris in Marine Settings, Philosophical Transactions of the Royal Society B: Biological Sciences 364(1526):2013-25.

Grün, Felix, and B. Blumberg. 2009. "Endocrine Disrupters as Obesogens." Molecular and Cellular Endocrinology, Special Issue: Endocrine Disruptors from the Environment in the Aetiology of Obesity and Diabetes, 304 (1-2): 19-29.

Gutiérrez y Muhs, Gabriella, Y. Flores Niemann, C.G. González, and A.P. Harris. 2012. Presumed incompetent: The intersections of race and class for women in academia. Boulder: University Press of Colorado.

Halden, Rolf U. 2010. "Plastics and Health Risks." Annual Review of Public Health 31(1):179-94.

Hale, Charles R. 2006. "Activist Research v. Cultural Critique: Indigenous Land Rights and the Contradictions of Politically Engaged Anthropology." Cultural Anthropology 21(1):96-120.

Hallett, Vicki S. 2016. "Cold Water Cowboys and Newfoundland Masculinity." Acadiensis, June 13. Accessed July 8, 2017. https://acadiensis.wordpress.com/2016/06/13/cold-watercowboys-and-newfoundland-masculinity/

Harding, Sandra. 2016. Whose science? Whose knowledge?: Thinking from women's lives. Ithaca: Cornell University Press.

Heller, Michael A., and R.S. Eisenberg. 1998 "Can patents deter innovation? The anticommons in biomedical research." Science 280(5364):698-701. 
Heller, Michael. 2010. The Gridlock Economy: How Too Much Ownership Wrecks Markets Stops Innovation, and Costs Lives. New York: Basic Books.

Hayden, C. 2007. "Taking as giving: Bioscience, exchange, and the politics of benefit-sharing." Social Studies of Science 37(5):729-758.

Holloway, J. 1992. "Crisis, fetishism, class composition," in: Open Marxism, Vol. 2, edited by W. Bonefeld, R. Gunn and K. Psychopedis. London: Pluto Press.

Hope, Janet. 2009. Biobazaar: the open source revolution and biotechnology. Cambirdge: Harvard University Press.

Hughes, Thomas P. 1987. "The evolution of large technological systems." In The social construction of technological systems: New directions in the sociology and history of technology, edited by W.E. Bijker, T.P Hughes, T. Pinch, and D.G. Douglas, 51-82. Cambrdge: MIT Press.

Illich, Ivan, and A. Lang. 1973. Tools for conviviality. London: Boyars.

Klein, Hans K., and D.L. Kleinman. 2002. "The social construction of technology: Structural considerations." Science, Technology, \& Human Values 27(1):28-52.

Kleinman, Daniel Lee. 1998. "Untangling context: Understanding a university laboratory in the commercial world." Science, Technology, \& Human Values 23(3):285-314.

Kleinman, Daniel Lee, and R. Osley-Thomas. 2014. "Uneven commercialization: Contradiction and conflict in the identity and practices of American universities." Minerva 52(1):1-26.

Knobel, Cory, and G.C. Bowker. 2011. "Values in design." Communications of the ACM 54(7):26-28.

Kranakis, Eda. 2007. "Patents and power: European patent-system integration in the context of globalization." Technology and Culture 48(4):689-728.

Kuhn, Thomas S. 1970. The Structure of Scientific Revolutions. Chicago: University of Chicago Press.

Law, John. 1991. "Power, discretion and strategy." In A sociology of monsters, edited by John Law, 165-91. London: Routledge.

Lave, Rebecca, P. Mirowski, and S. Randalls. 2010. "Introduction: STS and neoliberal science." Social Studies of Science 40(5):659-675.

Lentacker, Antoine. 2016. "The symbolic economy of drugs." Social Studies of Science, 46(1):140-156.

Liboiron, Max. 2016a. "Redefining pollution and action: The matter of plastics." Journal of Material Culture 21(1):87-110.

Liboiron, Max. 2016. "Civic Technologies for Monitoring Marine Plastics." Journal of Ocean Technology 11(2):36-45.

Liboiron, Max, and J. Molloy. 2017. "We need to break science out of its ivory tower-here's one way to do so." The Conversation. April 25. Accessed July 7, 2017. https:// 
theconversation.com / we-need-to-break-science-out-of-its-ivory-tower-heres-one-way-todo-this-76354

Lorde, Audre. 2012. Sister outsider: Essays and speeches. Berkeley, CA: Crossing Press.

Lubar, Steven. 1991. "The transformation of antebellum patent law." Technology and Culture 32(4): 932-959.

Mato, Yukie, T. Isobe, H. Takada, H. Kanehiro, C. Ohtake, and T. Kaminuma. 2001. "Plastic resin pellets as a transport medium for toxic chemicals in the marine environment." Environmental science \& technology 35(2):318-324.

McQuillan, Dan. 2014. "The countercultural potential of citizen science." M/C Journal 17(6).

Memorial University of Newfoundland, Office of the Vice-President (Research). 2015. "Memorial University's Technology Transfer and Commercialization Strategy." St. John's, Nefoundland: Memorial University of Newfoundland and Labrador.

Mercelis, Joris. 2012. "Leo Baekeland's transatlantic struggle for Bakelite: patenting inside and outside of America." Technology and Culture 53(2):366-400.

Merson, John. 2000. "Bio-prospecting or bio-piracy: intellectual property rights and biodiversity in a colonial and postcolonial context." Osiris 15:282-296.

Mgbeoji, Ikechi. 2014. Global biopiracy: patents, plants, and indigenous knowledge. Vancouver: UBC Press.

Miller, D. P. 2008. "Intellectual Property and narratives of discovery/invention: The league of nations' draft convention on 'scientific property' and its fate." History of Science 46(3): 299-342.

Moreton-Robinson, Aileen. 2015. The white possessive: Property, power, and indigenous sovereignty. Minneapolis: University of Minnesota Press.

Mowery, David C., R.R. Nelson, B.N. Sampat, and A.A. Ziedonis. 2001. "The growth of patenting and licensing by US universities: an assessment of the effects of the Bayh-Dole act of 1980." Research policy 30(1):99-119.

Murphy, Michelle. 2017. The Economization of Life. Durham, NC: Duke University Press.

Nader, Laura. 1972. "Up the anthropologist: perspectives gained from studying up." In Reinventing Anthropology edited by D.H. Hymes, 284-311. New York: Pantheon Books.

Napper, Imogen E., A. Bakir, S.J. Rowland, and R.C. Thompson. 2015. “Characterisation, Quantity and Sorptive Properties of Microplastics Extracted from Cosmetics." Marine Pollution Bulletin 99(1-2):178-85. 
Negri, Antonio. 1996. "Twenty theses on Marx: Interpretation of the class situation today." In Marxism Beyond Marxism edited by S. Makdisi, C. Casarino and R. Karl, 149-180. Hove, UK: Psychology Press.

O'Reagan, Douglas. 2017. "Know-How in Postwar Business and Law." Technology and Culture 58(1):121-153.

Oldenziel, Ruth. 1999. Making technology masculine: men, women and modern machines in America, 1870-1945. Amsterdam: Amsterdam University Press.

PlasticsEurope. 2015. "Plastics- the Facts 2014/2015." PlasticsEurope. n.d. Accessed July 1, 2017. http: / / www.plasticseurope.org/Document/ plastics-the-facts-20142015.aspx.

Power, Nicole Gerarda. 2015. What do they call a fisherman?: men, gender, and restructuring in the Newfoundland fishery. St. John's, NL: ISER Books.

Power, Nicole Gerarda. 2008. "Occupational risks, safety and masculinity: Newfoundland fish harvesters' experiences and understandings of fishery risks." Health, Risk \& Society 10(6): 565-583.

Quigley, Andrea, H. Efford and K. Rees. 2015. "Making Plastic Public, Penile, and Unpleasant: Design \& Final Report from P.E.N.I.S. Handlers." April 24. Class report. Department of Sociology, Memorial University of Newfoundland.

Riesch, Hauke, and C. Potter. 2014. "Citizen science as seen by scientists: Methodological, epistemological and ethical dimensions." Public Understanding of Science 23(1):107-120.

Rochman, Chelsea M., E. Hoh, T. Kurobe, and S.J. Teh. 2013. "Ingested plastic transfers hazardous chemicals to fish and induces hepatic stress." Scientific reports 3: 3263.

Rodriguez, Victor, F. Janssens, K. Debackere, and B.De Moor. 2017. "Do material transfer agreements affect the choice of research agendas? The case of biotechnology in Belgium." Scientometrics 71(2):239-269.

Rowe, Aimee Carrillo, and E. Tuck. 2017. "Settler colonialism and cultural studies: Ongoing settlement, cultural production, and resistance." Cultural Studies $\leftrightarrow$ Critical Methodologies 17(1):3-13.

Sandoval, Chela. 2000. Methodology of the Oppressed. Minneapolis: University of Minnesota Press.

Scassa, T., and H. Chung. 2015. "Typology of citizen science projects from an intellectual property perspective." Washington, DC.: Wilson center-Commons Lab. Accessed July 7, 2017. https: / / www.wilsoncenter.org/ sites/default / files / Typology_of_Citizen_Science_IP_Rights_Scassa.pdf

Scott, James. 1985. Weapons of the Weak: Everyday Forms of Peasant Resistance. New Haven: Yale University Press. 
Scott, W. Richard. 1995. Institutions and organizations. Foundations for organizational science. London: Sage Publication Series.

Shotwell, Alexis. 2016. Against Purity: Living Ethically in Compromised Times. Minneapolis: University of Minnesota Press.

Söderberg, Johan. 2010. "Misuser inventions and the invention of the misuser: Hackers, crackers and filesharers." Science as culture 19(2):151-179.

Slack, J. 1984. Communication Technologies \& Society: Conceptions of Causality $\mathcal{E}$ the Politics of Technological Intervention. Norwood, NJ: Ablex.

Spivak, Gayatri Chakravorty. 2012. In other worlds: Essays in cultural politics. London: Routledge.

Suchman, Mark C. 1995. "Managing legitimacy: Strategic and institutional approaches." 20(3): 571-610.

Tanaka, Kosuke, H. Takada, R. Yamashita, K.Mizukawa, M. Fukuwaka, and Y. Watanuki. 2013. "Accumulation of plastic-derived chemicals in tissues of seabirds ingesting marine plastics." Marine pollution bulletin 69(1):219-222.

Tuck, Eve, and K.W. Yang. 2012. "Decolonization is not a metaphor." Decolonization: Indigeneity, education $\mathcal{E}$ society 1(1):1-40.

U.S. Energy Information Administration (EIA). 2015. "How Much Oil Is Used to Make Plastic?" July 10. Accessed July 7, 2017. http: / / www.eia.gov / tools / faqs / faq.cfm?id=34\&t=6.

Van Oost, Ellen. 2004. Materialized gender: How shavers configure the users' femininity and masculinity. Cambridge, MA: MIT Press.

Vom Saal, Frederick S., B.T. Akingbemi, S.M. Belcher, L.S. Birnbaum, D. Crain, M. Eriksen, F. Farabollini et al. 2007. "Chapel Hill bisphenol A expert panel consensus statement: integration of mechanisms, effects in animals and potential to impact human health at current levels of exposure." Reproductive toxicology 24(2):131.

Wajcman, Judy. 2010. "Feminist theories of technology." Cambridge journal of economics 34(1): 143-152.

Winner, Langdon. 1980. "Do artifacts have politics?." Daedalus:121-136.

Whitt, Laurie Anne. 1998. "Indigenous Peoples, Intellectual Property \& (and) the New Imperial Science." Okla. City UL Rev. 23: 211.

WHO/UNEP. 2013. "State of the Science of Endocrine Disrupting Chemicals - 2012." WHO/ UNEP. Accessed July 7, 2017. http: / / www.who.int/ceh/publications/endocrine/ en/.

Wolfe, Patrick. 1999. Settler colonialism. London, UK: A\&C Black.

Woolgar, Steve, and Geoff Cooper. 1999. "Do Artefacts Have Ambivalence: Moses' Bridges, Winner's Bridges and other Urban Legends in S\&TS." Social studies of science 29(3):433-449. 
Wylie, Sara Ann, K. Jalbert, S. Dosemagen, and M. Ratto. 2014. "Institutions for civic technoscience: How critical making is transforming environmental research." The Information Society 30(2):116-126. 